\title{
Reversed Differential Cyanosis in Two Neonates with Obstructed Supracardiac Total Anomalous Pulmonary Venous Drainage
}

ISSN: 2576-9200

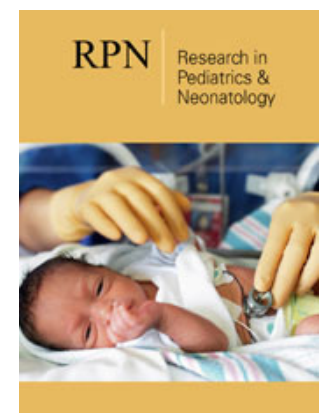

${ }^{* 1}$ Corresponding author: Pak-Cheong Chow, Department of Paediatric Cardiology, Queen Mary Hospital, Hong Kong SAR

Submission: 侮 October 07, 2019

Published: 㱕 October 31, 2019

Volume 3 - Issue 5

How to cite this article: Chow $\mathrm{PC}$, Chen RHS, Rocha BA, \& Yam NLH. Reversed Differential Cyanosis in Two Neonates with Obstructed Supracardiac Total Anomalous Pulmonary Venous Drainage. A Case Report. Res Pediatr Neonatol. 3(5). RPN.000574.2019.

DOI: $10.31031 /$ RPN.2019.03.000574

Copyright@ Pak-Cheong Chow, This article is distributed under the terms of the Creative Commons Attribution 4.0 International License, which permits unrestricted use and redistribution provided that the original author and source are credited.

\author{
Chow PC ${ }^{1 *}$, Chen RHS ${ }^{1}$, Rocha $\mathrm{BA}^{2}$ and Yam NLH ${ }^{2}$ \\ ${ }^{1}$ Department of Paediatric Cardiology, Hong Kong \\ ${ }^{2}$ Department of Cardiothoracic Surgery, Hong Kong
}

\begin{abstract}
We reported two neonates with obstructed supracardiac total anomalous pulmonary venous drainage (TAPVD) presented with reverse differential cyanosis. We reviewed the pathophysiology of supracardiac TAPVD in causing reverse differential cyanosis and highlighted the importance of considering TAPVD as the differential diagnosis to facilitate early treatment.
\end{abstract}

\section{Introduction}

Generalized cyanosis in newborn can be caused by many pathological conditions and cyanotic congenital heart disease represents one of the important causes. Differential cyanosis refers to the situation where upper limb saturation is higher than lower limb and it is well documented to be caused by persistent pulmonary hypertension in newborn (PPHN) [1] or patients with patent ductus arteriosus and Eisenmenger syndrome in adults [2-4]; Table 1. This has been also reported in a neonate with critical aortic stenosis, hypoplastic aortic arch, pulmonary hypertension and PDA [2]. Reversed differential cyanosis (RDC) refers to the situation when the oxygen saturation of upper limb is lower than that of lower limb, which was classically reported in neonates with transposition of great arteries (TGA) with pulmonary hypertension [2] or TGA with aortic arch obstruction or interruption [5-12]; Table 1. Other causes included supracardiac total anomalous pulmonary venous drainage (TAPVD) [13], isolated right subclavian artery [14], and infants on veno-arterial extracorporeal membrane oxygenation using right carotid artery for cannulation [15]. We herewith reported two cases of obstructed supracardiac TAPVD manifested reversed differential cyanosis.

\section{Case 1}

A male baby was born in regional hospital at 39 weeks of gestation through spontaneous vaginal delivery. Antenatal history was unremarkable. There is no maternal GBS carriage. Anomaly scan was unremarkable. The Apgar score was 8 at both first and fifth minutes of life. The birth weight was $2.81 \mathrm{~kg}$. Paediatric team was called to labour ward at 12 minutes of life because of desaturation down to $80 \%$. Physical examination showed tachypnoea (60 breath per min) with subcostal insucking, no murmur. The baby was initially ventilated with nasal CPAP with $100 \%$ oxygen. The lower limb oximetry was increased to $100 \%$ but the right upper limb oxymetry remained at $80-85 \%$. Patient was transferred to NICU and was intubated. Both conventional and high frequency ventilation was attempted. Chest X-ray at 2 hours of life showed bilateral streakiness with blurred heart border Figure 1a \& 1b. First arterial blood gas showed pH 7.32, pCO2 5.6kPa, p)2 5.4kPa, HCO3 21.6mmol/l, BE -4.4. The baby was treated as PPHN and inhaled nitric oxide (iNO) 20ppm was administered. Upper limb-lower limb oxymetry difference remained similar with right upper limb SpO2 around 80-85\% and lower limb Sp02 95-96\%. In view of reversal differential cyanosis, PGE2 infusion at $0.005 \mathrm{mcg} / \mathrm{kg} /$ min was started. Echocardiogram in the regional NICU could not identify cardiac cause of the differential cyanosis but showed hypertrophic and dilated right ventricle, bulging of the ventricular septum to the left, smallish left ventricle, a large atrial communication and no feature of transposition of great arteries. 


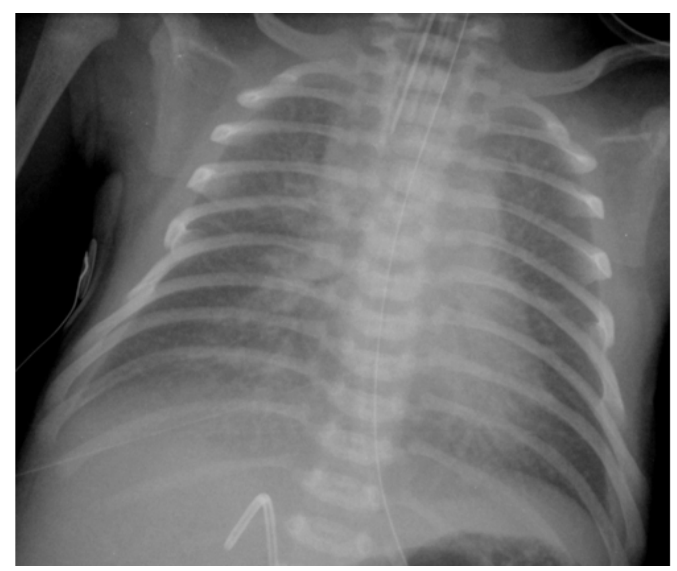

Figure 1. CXR 2 hours after birth of case 1.

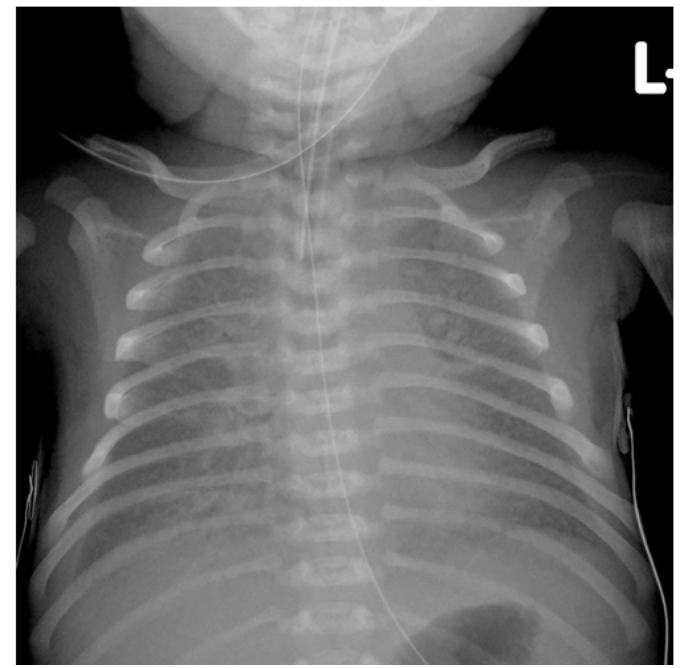

Figure 1b. CXR 9 hours after birth of case 1 .

Our team was consulted and performed echocardiogram at the regional hospital which found supracardiac total anomalous pulmonary venous drainage (TAPVD) with obstructed flow along ascending vein (Doppler-derived mean gradient of $9 \mathrm{mmHg}$ ), nonrestrictive patent foramen ovale with right-to-left shunting (Figure 2a \& 2b), a moderate-sized patent ductus arteriosus (3.3mm) with predominant right-to-left shunting. Further examination showed preferential flow of IVC blood via non-restrictive atrial communication to left atrium which may explain the relatively lower oxygen saturation in the ascending aorta and the upper limbs; while high flow from SVC streamlining caudally to the right ventricle together with predominant right-to-left shunting through a moderate sized duct channelled oxygenated blood to the descending aorta and the lower limbs Figure 2c. The baby was then emergently transferred to our centre for surgical repair. A repeated chest X-ray at 9 hours of life showed progressive pulmonary venous congestion (Figure 1b). On arrival to operation suite, the pulse pressure was reduced and there was further desaturation. Surgical repair of TAPVD was performed at 12 hours of life. Incision was made across the common pulmonary venous chamber extending to all four pulmonary veins. A large incision was made on left atrium which was anastomosed to the edge of the pulmonary venous chamber incision on the right side, and "sutureless" technique was adopted over the mid portion and the left side.

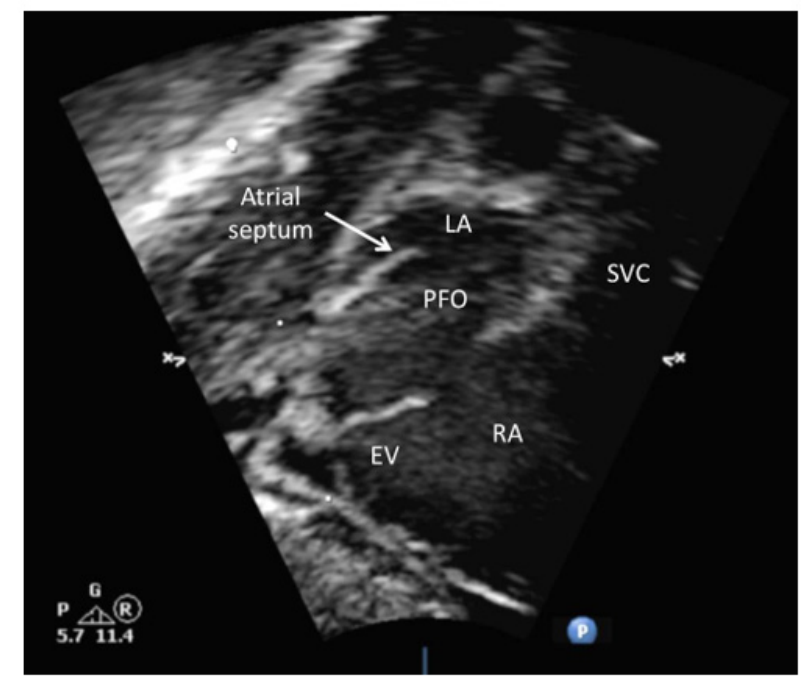

Figure 2a. 2D echo showing widely patent foramen ovale, EV, Eustachian valve, LA, left atrium, PFO, patent foramen ovale, RA, right atrium, SVC, superior vena cava.

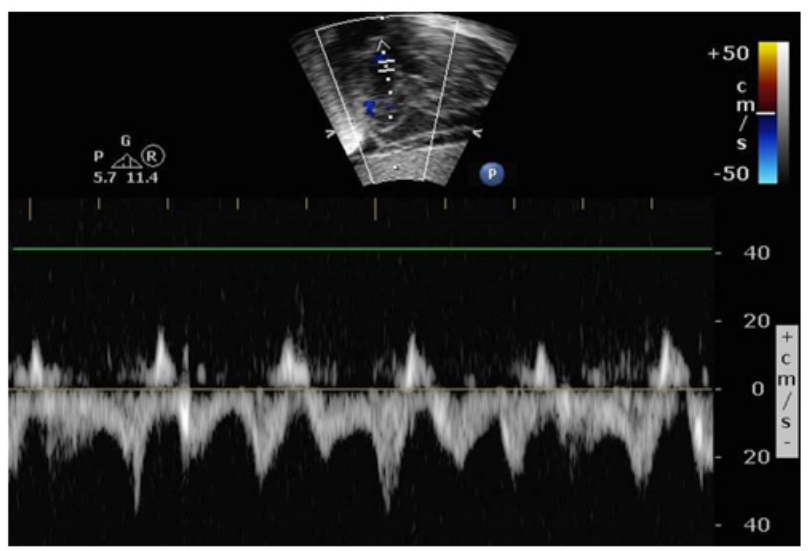

Figure 2b. Pulse wave Doppler showed unrestrictive right-to-left shunting across the patent foramen ovale.

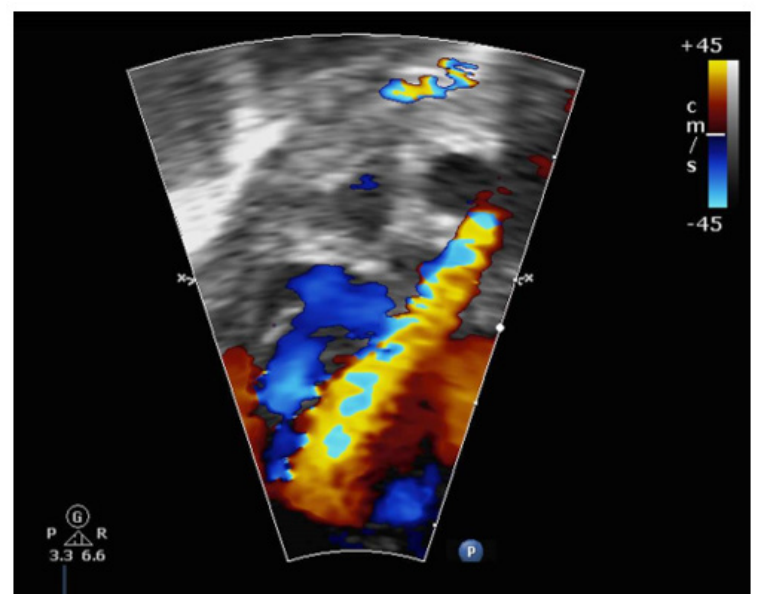

Figure 2c. Colour flow mapping showed high velocity SVC flow (aliasing flow) streaming caudally to RV and IVC blood (blue) streaming toward PFO. 
Table 1: Causes of differential cyanosis.

\begin{tabular}{|c|c|}
\hline $\begin{array}{l}\text { Differential Cyanosis } \\
\mathrm{UL} \mathrm{SaO}_{2}>\mathrm{LL} \mathrm{SaO}\end{array}$ & $\begin{array}{l}\text { Reversed Differential Cyanosis } \\
\mathrm{UL} \mathrm{SaO}_{2}<\mathrm{LL} \mathrm{SaO}_{2}\end{array}$ \\
\hline $\begin{array}{l}\text { - Severe pulmonary hypertension with PDA } \\
\text { - Severe aortic coarctation } \\
\text { H10(preductal) or interruption }\end{array}$ & $\begin{array}{l}\text { - Transposition of great arteries (or Double-outlet right ventricle with subpulmonary ventricular sep- } \\
\text { tal defect) with severe pulmonary hypertension and PDA - TGA with severe aortic arch obstruction / } \\
\text { interruption and PDA } \\
\text { - Supracardiac TAPVD with PFO and PDA } \\
\text { - Anomalous right subclavian artery connected by the ductus to the right pulmonary artery (Isolated } \\
\text { RSA) (RUL } \mathrm{SaO}_{2} \text { lower than LUL and } \mathrm{LL} \mathrm{SaO}_{2} \text { ) }\end{array}$ \\
\hline
\end{tabular}

The surgical repair was performed with cardiopulmonary bypass time of $106 \mathrm{~min}$, aortic cross clamp of 34 minutes, and circulatory arrest time of 30 minutes at $20{ }^{\circ} \mathrm{C}$. Post-bypass transoesophageal echocardiography showed widely patent anastomosis between the pulmonary venous chamber and the left atrium, moderately dilated right ventricle with impaired systolic function, mild tricuspid regurgitation with estimated right ventricular systolic pressure (RVSP) being two-third systemic and a small residual atrial communication $1.5 \mathrm{~mm}$ with left-to-right shunting. Both upper and lower limb oximetry were the same at $98-100 \%$ after operation. Sternum was closed on post-operative day 2 . The resultant pulmonary venous drainage was satisfactory, but the left hemi-diaphragm was paretic.

\section{Case 2}

Five days after the first case, another male neonate with birth weight of $3.27 \mathrm{~kg}$ was born in the same referring hospital. The baby was born by normal vaginal delivery at 40 weeks of gestation with moderate amount of meconium-stained liquor. $\mathrm{He}$ was found to have respiratory distress at birth and desaturation. Oximetry of right upper limb was $84 \%$ and that of lower limb was $90 \%$ while on nasal CPAP $7 \mathrm{~cm} \mathrm{H2O}$. The baby was intubated with mechanical ventilation using SIMV mode with PIP 24, PEEP 6 rate 50 FiO2 0.6. CXR showed bilateral lower zone haziness, and he was treated as meconium aspiration pneumonia initially with intravenous penicillin and gentamicin. Reverse differential cyanosis persisted with RUL oximetry of 89-90\%, LL oximetry of 93-95\%. Echocardiogram showed dilated RA and RV, smallish LA and LV, right-to-left shunting via PFO, pulmonary venous chamber draining to right-sided SVC, PDA of $5 \mathrm{~mm}$ with bidirectional shunt. The findings suggested supracardiac type TAPVD with obstruction. The baby was transferred to our cardiac centre and emergency TAPVD repair was performed. Intraoperative findings included a transversely-oriented and smallish pulmonary venous chamber received all 4 pulmonary veins draining through a $2-3 \mathrm{~mm}$ ascending vein which ran posteriorly and joined the SVC close to the innominate vein junction, and a large PDA of $6 \mathrm{~mm}$. Surgical repair of TPAVD was performed under circulatory arrest of 35 minute at $20 \mathrm{oC}$, with the anastomosis of the pulmonary venous chamber to the left atrium using a continuous 7-0 Prolene with "sutureless" technique. Post-operatively, the pulmonary venous drainage to the left atrium showed no obstruction.

\section{Discussion}

We reported two cases of supracardiac TAVPD as the cause of RDC. Yap et al reported first case of mixed supracardiac TAPVD with no obstruction [13]. Taken together, supracardiac TAPVD should be considered as one of the differential diagnosis in RDC and detailed echocardiography to assess the pulmonary veins would be important in these sick neonates. The diagnosis is obviously important because TAPVD is amenable to surgical repair and timely operation is needed if there is obstruction of the pulmonary venous drainage. From our echocardiographic images, three characteristics are present to be the pre-requisite for supracardiac TAPVD to present RDC. First, the atrial communication is not restrictive and flap-like, which allows streaming of deoxygenated blood from IVC to the left atrium. This causes lower saturation in left ventricle, ascending aorta and the brachiocephalic vessels. Second, there is high flow of oxygenated blood from SVC streamling caudally to the right ventricle. The saturation in SVC is much higher than that of IVC due to the abnormal supracardiac drainage of all pulmonary veins to SVC. This also causes high velocity flow within the SVC, such high-velocity flow permits the highly oxygenated blood flowing into the right ventricle and limits mixing with deoxygenated blood from IVC. Third, the ductus arteriosus is relatively sizeable allowing oxygenated blood shunting from pulmonary artery to descending aorta. Combining these three features, the deoxygenated blood flow from IVC across the atrial communication and reaches the left heart. That makes lower saturation in the brachiocephalic vessels. At the same time, the high-velocity flow of oxygenated blood from SVC streamlines to the right ventricle, which leads to higher saturation in the pulmonary artery, ductus arteriosus and the descending aorta.

Knowing TAPVD as one of differential diagnosis of RDC is important on two aspects. Obviously early diagnosis should be achieved, and emergent surgical repair is required especially if there is obstruction as in our case. Second issue is related to initial management, while it is generally recommended to start IV PGE2 or even pulmonary vasodilator in the setting of cyanotic heart diseases with reduced pulmonary blood flow or PPHN. This treatment strategy would potentially aggravate the pulmonary congestion in the setting of obstructed TAPVD. Therefore, TAPVD should be excluded when the neonates presented with reversed differential cyanosis. 


\section{Conclusion}

Two cases of supracardiac TAPVD presented with reversed differential cyanosis. The presence of reverse differential cyanosis should prompt the necessary investigation to achieve early diagnosis and early surgical repair especially in the case with obstructed pulmonary venous drainage.

\section{References}

1. Lakshminrusimha S, Konduri GG, Steinhorn RH (2016) Considerations in the management of hypoxemic respiratory failure and persistent pulmonary hypertension in term and late preterm neonates. J Perinatol 36 (Suppl. 2): S12-S19.

2. Hipona FA, Sanyal SK (1968) Differential cyanosis in congenital heart disease. J Pediatr 72(2): 194-200.

3. Moccetti F, Kaufmann BA, Tobler D. (2014) Differential clubbing and cyanosis: a pathognomonic finding in cardiology. Eur Heart J 35(21): 1410.

4. Sabnis GR, Phadke MS, Lanjewar CP, Kerkar PG, Nabar AA (2014) Differential cyanosis and clubbing sparing a single limb. Journal of the American College of Cardiology 63(14): e33.

5. Hamburger LP (1937) Congenital cardiac malformation presenting complete interruption of the isthmus aortae with transposition of the great arteries. Bull Johns Hopk Hosp 61: 421.

6. Buckley MJ, Mason DT, Ross J Jr, Braunwald E (1965) Reversed differential cyanosis with equal desaturation of the upper limbs, syndrome of complete transposition of the great vessels with complete interruption of the aortic arch. Am J Cardiol 15(1): 111-115.

7. Bowers DE, Schiebler GL, Krovetz LJ (1965) Interruption of the aortic arch with complete transposition of the great vessels. Hemodynamic and angiocardiographic data of a case diagnosed during life. Am J Cardiol 16(3): 442-448.
8. Aziz K, Sanyal SK, Goldblatt E (1968) Reversed differential cyanosis. Br Heart J 30(2): 288-290.

9. Scheeweiss A, Shem-Tov A, Blieden LC, Deutsch V, Neufeld HN (1981) Interruption of the aortic arch with complete transposition of the great arteries. Clinical and angiocardiographic diagnosis at the age of one day. Angiology 32(3): 208-211.

10. Roofthooft MT, Bergman KA, Waterbolk TW, Ebeis T, Bartelds B, et al. (2007) Persistent pulmonary hypertension of the newborn with transposition of the great arteries. Ann Thorac Surg 83(4): 1446-1450.

11. Goissen C, Ghyselen L, Tourneux P, Krim G, Storme L, et al. (2008) Persistent pulmonary hypertension of the newborn with transposition of the great arteries: successful treatment with bosentan. Eur J Pediatr 167(4): 437-440.

12. Martin TC (2011) Reverse Differential Cyanosis: a treatable newborn cardiac emergency. Neo Reviews 12(5): e270-e273.

13. Yap SH, Anania N, Alboliras ET, Lilien LD (2009) Reversed differential cyanosis in the newborn: a clinical finding in the supracardiac total anomalous pulmonary venous connection. Pediatr Cardiol 30(3): 359362 .

14. Keagy KS, Schall SA, Herrington RT (1982) Selective cyanosis of the right $\mathrm{arm}$. Isolation of right subclavian artery from aorta with bilateral ductus arteriosus and pulmonary hypertension. Pediatr Cardiol 3(4):301-303.

15. Di Nardo M, Stoppa F, David P, Lorusso R, Ranieri VM, et al. (2017) Reversed differential cyanosis during veno-arterial extracorporeal membrane oxygenation in infants: the reevaluation of an old phenomenon. Eur J Heart Fail 19 (Suppl. 2): 117-119.

For possible submissions Click below: 